\title{
INTERPRETATION AND EDUCATION IN NATURE CONSERVATION
}

\section{J T GEDDES PAGE}

\author{
Director \\ Natal Parks Game and Fish Preservation Board \\ PO Box 662 \\ Pietermaritzburg \\ 3200
}

It is pleasant to have an opportunity to deal with the subject of interpretation in nature conservation at a time when so many diversified and often ingenious efforts over the years are becoming formalized into systems with specially trained personnel supplied with specific and reasonable budgets to enable them to really get on with the job.

Preparations for the writing of this paper have led to the decision that education in nature conservation, although unquestionably running as a thread throughout most of our interpretative efforts is truly a very different approach. From earliest 'pupil' nature studies of old faithfuls like the grasshopper and the mealie to the most sophisticated university courses involving most intricate ecological studies of environmental interests, and the most valuable educational programmes of volunteer Societies, education must, in the main, yield pride of place in this contribution to interpretation as practiced by the professionals privileged to control visiting in proclaimed parks, game and nature reserves in the Republic of South Africa (RSA) today. Indulgence is, however, sought for references to overseas examples and illustrations which in fact so often form the basis of our own efforts.

\section{Objectives}

If education is the "hard sell" approach for nature conservation, interpretation should be the "soft sell" part of our approach to its primary objective of increasing visitor satisfaction and enjoyment. Management objectives can, however, also be facilitated and a high degree of public understanding of the policies of the nature conservation authority can also be obtained. Ecological objectives of interpretation include telling the whole natural story by interrelating all plant and animal communities with other natural features of the environment. The identification of the "superlatives', like the "biggest", "oldest" and "smallest" all adds to visitor enjoyment and often simplifies the task of protecting the "rarest" of species for which we are responsible. 


\section{Tilden's Principles}

Tilden's six principles of interpretation are restated as follows:

(i) relate interpretative features to something within the experience of the visitor;

(ii) interpretation must cover more than information; why is it there?, what are its significance and implications?, and what is NOT known about it?;

(iii) interpretation is an art; using all the senses to build concepts and to communicate;

(iv) interpretation must be presented as a whole; interrelate features and stories into a conceptual entity;

(v) interpretation is provocation; arousing curiosity by describing significance and implications; and

(vi) interpretation should be variously directed to specific audiences; children or adults for example.

\section{Available media}

Media most suited for interpretational use include:

(i) personal contact through information desk welcoming staff, guided tours and personal talks;

(ii) simulated personal services like recorded audio and visual messagerepeaters;

(iii) written material like signs, labels, published brochures, checklists and guides;

(iv) self-guided nature trails along 'loop' routes where the visitor increases his enjoyment by 'teaching' himself from specially written and illustrated pamphlets;

(v) indoor and outdoor displays telling brief interesting facts illustrated by pictures, dendrograms, models, etc; and

(vi) visitor centres which can combine most of these features concentrated upon one point. They must be easy of access; include reception desk, auditorium, exhibit area, rest rooms, staff rooms. They usually cost a lot of money, but the value of such investments is incalcuable. Visitor centres should ideally be constructed on good quality natural sites en route between entrance and accommodation. They should preferably be sited separated from other buildings and designed to blend into the environment concerned.

Naturally it has to be accepted that the provision of a full interpretative service can seldom just 'happen'. Small starts are more usually the beginnings which can be built up to the ideal of a Visitor Centre for every major reserve combined with educational programmes provided by the nature conservation authority, by schools, universities, zoos, and voluntary conservation societies. 


\section{Considerations}

Factors which are well worth consideration before deciding upon interpretational programmes include:

(i) where visitors come from and in what proportions;

(ii) the average numbers in visitor parties;

(iii) their ages and educational levels; and

(iv) the average length of stays and numbers of 'repeater' visitors.

Well designed interpretation programmes could embrace all or some of the following steps, although the priorities are not necessarily inflexible:

(i) an inventory of what the reserve has to offer;

(ii) the erection of elementary directional and interpretational signs;

(iii) the selection of interesting natural features to form the basis of a nature trail and preparation of self-guiding pamphlets for such trails;

(iv) roadside stops, shelters and artwork;

(v) the appointment of (perhaps seasonal) a ranger(s) (naturalist) and preparation of evening talks; preparation of slides and arranging use of films etc. Initially senior students and junior university lecturers offer good holiday-staff material;

(vi) the remodelling of an existing building as a visitor centre; the preparation of models, displays, audio and video aids plus further nature trails;

(vii) the appointment of one or more full time naturalists and perhaps, other part-time naturalists - the preparation of radio and television programmes and the expansion of publications and their distribution; and

(viii) the construction of a properly designed visitor centre/s and stepping up of whole programmes and so on. A future as wonderful as those concerned choose to make it! Surely none can doubt the importance of concentration upon this field so vital to beneficial conservation-experiences for the "piper who plays the tune" - the taxpayer.

\section{Progress}

Let us deal first with the Provincial Nature Conservation Authorities and the National Parks Board of Trustees collectively as "the professionals" and secondly with some details of the invaluable work of volunteer Societies, "schools" and other operators of educational safaries or trails.

\section{The National and provincial authorities}

Pride of place in this general field belongs perhaps to the Cape Province. The Inland Fisheries Department, forerunner of the present nature conservation authority in that Province, started in the 'forties' and 'fifties' with publications designed to inform the public on nature 
conservation subjects and most of us are familiar with their delightful and informative booklets on protected cape flora; "The Culture of Freshwater Fish in South Africa"; "The Keeping of Fish in Ponds and Aquaria"; handbooks on Waterfowl and Wildlife Management and the propagation of Wild Flowers. Dr D Hey deserves special mention for his pioneering work in producing most of these publications, for posters, stickers, radio programmes and regular press features; also for his early personal nature conservation films and for the wonderful educational efforts of the museums of that Province.

More generally, we find that all the Provinces and the National Parks Board of Trustees offer informative annual reports, scientific papers (often in journals rapidly becoming well known like Koedoe, Madoqua and Lammergeyer) as well as brochures, maps and other publications. In addition, growing information and extension services exist, staffed specifically by professional, administrative and technical personnel, but assisted by virtually all the experienced officers in the employ of these authorities who are expected to be willing and able to provide lectures, slide and film illustrated talks to interested clubs, societies and to the public generally.

In the Orange Free State lecturing and nature trails arranged in close collaboration with the education department have proved a great success. The young are considered an especially fertile field in which to sow and cultivate the nature conservation messages. Nature trails, accompanied by experienced interpretative officers (naturalists), who are able to put across the nature conservation story to visitors are popular features in increasing numbers of reserves and national parks. Individual feature films have been made in the past but television features have also been produced and others are planned as this most powerful medium must be used to best advantage in future.

Excellent interpretative and aquarium exhibits exist in the head office of the National Parks Board of Trustees, as well as in the head office of the Division of Nature Conservation in Pretoria. Progress with the building and furnishing of visitor centres at Blyde Canyon by Transvaal and at Giant's Castle and Royal Natal by the Natal Parks Board deserve special mention, whilst the Stevenson Hamilton Library in the Kruger National Park and other visitor centres in national parks throughout the RSA have long made important contributions in this important field.

Many of the Provincial Departments, Divisions and the Natal Parks Board concentrate upon agricultural and other specialised shows as excellent media for contact with the farming community. Prominence has been given to game capture techniques and to the desirability of restocking depleted areas with species which previously occurred there.

The previously mentioned educational services of the Cape's museums are duplicated by all the National and Provincial museums, to a greater or lesser degree, and form an integral part of the cultural lives of many towns and cities in South Africa. The efforts of the National 
Zoological Gardens in Pretoria, however, also deserve special mention. Lectures given by trained personnel are aimed at school children, students and adult audiences, and a few statistics indicate the scope and importance of this service.

Financial Years: 1973/74

$\begin{array}{rrrr}\text { Attendance } & \text { Lectures given } & \text { Attendance } & \text { Lectures given } \\ 602 & 68190 & 1161 & 100795\end{array}$

Since the 1969/70 financial year, the service has expanded $300 \%$ with $80 \%$ of all visitors now visiting both the Zoological Gardens and the new Aquarium and only $20 \%$ visiting only the one or the other. Programmes are designed particularly:

(i) to emphasise that certain species are endangered - thereby bringing to the attention of the individual visitor the importance of nature conservation;

(ii) to create an interest in the creatures displayed and the countries whence they originated, and

(iii) to stimulate visitors to contribute financially or personally to conservation efforts which are presented in the light of their economic, scientific, aesthetic, recreational and prestige values.

Whereas it is true that many non-indigenous species loom large in zoological garden exhibits, our national organisation has made great strides in using man's fascination for most wild creatures to highlight the importance of nature conservation in our own country.

\section{The other organisations}

(a) It must be clearly repeated that it has proved beyond the ability of the author to cover the basic and extremely valuable contributions of all education departments (both provincial and national), the universities and institutes (often linked to those universities) to the fields of interpretation and nature conservation education in the RSA and it is to be hoped that other may be able to catalogue those efforts elsewhere in due course.

(b) Of the wildlife and hunting-orientated societies, the efforts of the Wildlife Society of South Africa through its various branches and, in particular, in association with other organisations, deserve particular attention. The Society has the largest membership of any comparable group in the RSA and through its meetings, lectures, film shows and particular educational programmes it reaches a huge public.

Further planning within the Society includes a multi-racial educational project for scholars and teacher training throughout southern Africa. Practical involvement will, it is hoped, become an 
integral part of schooling, from primary to matric standards, all designed to promote a positive attitude among young South Africans, with field excursions serving as an educational and recreational outlet offering opportunities for aesthetic experiences of the wonders of nature under the guidance of trained staff. It is not the wish of the Society to usurp the functions of any education authority, but rather to compliment, encourage and assist them to reach the young and to provide the tools, in many cases, so that the job may better be done. In the latter regard, it is to be hoped that this programme will greatly increase the audio-visual aids available for educating the young.

(c) "Joint Venture" is singled out as a particular programme prepared and executed in Natal by the combined efforts of the Wildlife Society, the Wilderness Leadership School and the Natal Hunters Association. Launched in 1974, Joint Venture was aimed at creating a conservation awareness among children between 11 and 16 years of age. Many have contributed to the success of this scheme which offers courses in the Umgeni Valley Game Ranch, the Karkloof Environmental Education Park, the Inanda Park and at the Midmar Public Resort.

(d) The Wilderness Leadership School and Veld \& Vlei are now world famous for their efforts to assist in producing better leaders for the future by exposing the young (and perhaps some of the not so young) to experiences of a personal 'testing' type either specifically in wildnerness areas or generally through contact with natural environments and with the effects of the forces of nature.

\section{Conclusion}

It must be expected in a presentation of this kind that the efforts of some organisations or individuals will have been missed and others, perhaps, over emphasised as a result of the personal experiences and knowledge of the author. Let none of these aspects detract from the most important fact which, it is hoped, should emerge from this paper and that is how fortunate we are in the RSA that so many are concious of the need for nature conservation. Never before have so many actively sought knowledge and experience in this field; never before have so many been ready, willing and able to offer time and effort to supply the demand. Once again it is reiterated that we have (all of us) good cause to give thanks for a hopeful and ever-improving prognosis for the future of nature conservation in South Africa. It could be considered irresponsible not to confirm the need for all to increase our efforts, especially in the fields of nature conservation, interpretation and education, but let us also take time off from all our important and continuing battles to improve our lot, to consider for a moment just how lucky we are for what we already have to enjoy. 